Artigos

Volume 8 - 2018|n. 2

\title{
A Gestão da Educação Infantil em 12 Municípios Paulistas
}

\author{
Bianca Cristina Correa \\ Universidade de São Paulo (USP), Ribeirão Preto/SP - Brasil
}

\section{Resumo $^{1}$}

O trabalho apresenta dados de uma pesquisa cujo objetivo geral é analisar como se organiza a gestão da Educação Infantil (EI) e suas relações com a qualidade. Para tanto, foram aplicados questionários em 12 municípios que compõem uma microrregião paulista. Tais questionários visavam ao conhecimento da estrutura das Secretarias ou Departamentos de Educação e das unidades de El em cada município. Foram analisados, ainda, dados sobre os Estatutos do Magistério e Planos de Carreira, bem como sobre o Conselho Municipal de Educação. Os resultados nos mostraram: estruturas frágeis; número insuficiente de profissionais nas unidades de El; desconhecimento de dados fundamentais para planejar a ampliação da oferta de vagas; relações de mando e submissão; desigualdades em termos de remuneração e jornadas; permanência de contratação de "outros" profissionais, e não de docentes, para atuar com as crianças.

Palavras-chave: Gestão Educacional. Educação Infantil. Qualidade da Educação.

\section{Management of Early Childhood Education in 12 Municipalities of São Paulo State}

\section{Abstract}

The paper analyzes how the management of Early Childhood Education (ECE) is organized and its relationships with quality. For that, questionnaires were applied in 12 municipalities of a micro-region of São Paulo state. These questionnaires sought to know the structure of the Secretariats or Departments of Education and of ECE units in each municipality. Data from Teacher Statutes and Career Plans, as well as from the Municipal Councils of Education were also analyzed. The results showed the existence of fragile structures, insufficient number of professionals in ECE units, lack of knowledge about crucial educational data to plan the expansion of vacancies, command and submission relations, inequalities in terms of remuneration and working hours, and the hiring of "other" professionals, not teachers, to work with children.

Keywords: Educational Management. Child Education. Quality of Education.

Este trabalho, com pequenas diferenças, foi aceito como "excedente" na $37^{\text {a }}$ Reunião anual da Anped, ocorrida no ano de 2015. 
A Gestão da Educação Infantil em 12 Municípios Paulistas

\section{Introdução}

A Educação Infantil (El) em nosso país, a partir da Constituição Federal de 1988 (BRASIL, 1988), vem ganhando espaço no que se refere à legislação e às orientações oficiais em âmbito federal. Quanto aos estudos sobre essa etapa educacional, podemos afirmar que as pesquisas e a produção de artigos científicos também se ampliaram e, a partir de 2000, boa parte delas focou a qualidade como tema de investigação (CAMPOS; FULLGRAF; WIGGERS, 2006; CAMPOS; CRUZ, 2006; CORREA, 2003; FARIA; PALHARES, 1999; ROSEMBERG; CAMPOS, 1998).

Todavia, se por um lado podemos encontrar produções sobre a participação familiar na Educação Infantil, desenvolvidas ainda na década de 1990 (SOUZA; KRAMER, 1991; HADDAD, 1993), por outro, pesquisas voltadas especificamente ao exame da gestão nessa etapa educacional, seja no âmbito das creches e pré-escolas (denominadas doravante como unidades de El) seja no âmbito das redes de ensino, ainda são escassas no Brasil.

Dentre alguns dos estudos e artigos científicos nacionais e internacionais disponíveis que de alguma maneira discutem a gestão na EI (CORREA, 2001; 2006; BHERING; NEZ, 2002; BORGHI, 1998; CAMPOS, 2012; CÔCO, 2009; GARCIA; MACEDO, 2011; GUNNARSSON, 1998; JENSEN, 1994; KRAMER; NUNES, 2007; MELLO, 1998; SPAGGIARI, 1998; ZABALZA, 1998), dois aspectos chamam a atenção: por um lado, o próprio fato de haver um número restrito de trabalhos voltados especificamente ao tema e, por outro, o de que alguns desses estudos, embora não tivessem como objetivo específico analisar a gestão, concluíram que ela é uma das principais dimensões quando se analisa a qualidade na El.

Assim, essa lacuna de estudos sobre a gestão na/da El talvez possa explicar algumas das dificuldades ainda presentes nessa etapa educacional. Além disso, diante da importância dessa etapa educacional como parte da Educação Básica Nacional, da nova legislação que torna obrigatória a matrícula a partir dos quatro anos de idade na pré-escola, do crescente aumento da demanda por vagas em creches e do baixo percentual de matrículas ainda existente em nosso país, consideramos urgente a realização de estudos que mapeiem as condições de organização das redes e sistemas municipais de educação tendo como foco a gestão da El.

Este trabalho procura responder, ainda que parcialmente, essa lacuna, apresentando dados da primeira etapa de uma pesquisa que tem como objetivo geral mapear e analisar como se organiza a gestão da/na El em uma microrregião do Estado de São Paulo e suas relações com a qualidade. Destaque-se que, embora não tratemos estritamente das questões afetas ao financiamento da educação, campo de abrangência desta Revista, os dados sobre a organização dos sistemas e redes de educação, bem como sobre as condições de oferta da El em 12 municípios se relacionam diretamente aos desafios para se alcançar uma educação de melhor qualidade, o que, por sua vez, vincula-se aos recursos disponíveis para financiá-la. 
A Gestão da Educação Infantil em 12 Municípios Paulistas

\section{Procedimentos Metodológicos}

A pesquisa foi projetada para se desenvolver em duas etapas principais. Em primeiro lugar, buscou-se mapear os diferentes arranjos de gestão na $\mathrm{El}$, tanto no âmbito das Secretarias Municipais de Educação (SME) ou Departamentos de Educação (DPE) quanto no das unidades, em uma região do Estado de São Paulo composta por 16 municípios cujos indicadores educacionais são tão diversos quanto desiguais. A segunda etapa da pesquisa, em andamento, vem se desenvolvendo por meio de análise documental e estudos de caso em unidades de El pertencentes aos municípios que concordaram em colaborar.

$\mathrm{Na}$ primeira etapa, 12 municípios ( $75 \%$ do total) aceitaram participar e seus representantes assinaram Termos de Consentimento Livres e Esclarecidos; dois se recusaram, alegando dificuldades operacionais, e dois não responderam ao convite. Como uma das exigências para participar da pesquisa por parte de alguns municípios, seus gestores solicitaram anonimato, assim, estendemos essa condição para todos os demais. Em razão disso, neste trabalho os municípios citados serão designados por letras (eles foram enumerados de 1 a 12 e, seguindo a ordem alfabética, cada um recebeu uma letra, sem qualquer relação com seu nome real).

Aplicamos questionários pessoalmente em cada um dos 12 municípios. Em quatro deles fomos recebidos pelos próprios dirigentes das SME ou dos DPE, nos demais casos quem respondeu aos questionários e conversou conosco foram funcionários que ocupavam cargos de confiança na estrutura da SME ou DPE.

O questionário visava ao conhecimento da estrutura das SME/DPE e das unidades de El em cada município. Com esse instrumento buscamos levantar dados sobre os diferentes arranjos existentes para que pudéssemos, posteriormente, explicitar as possíveis relações entre as formas de gestão vigentes e os padrões de qualidade da El em cada município. Buscamos informações, dentre outras, sobre os cargos e/ou funções vinculados à gestão da/na Educação Infantil e o número de profissionais envolvidos; as formas de provimento de cargos ou funções de supervisor, diretor, vice-diretor e coordenador pedagógico para atuação na Educação Infantil; jornada de trabalho e remuneração desses profissionais. Solicitamos, complementarmente, cópia da legislação relativa à gestão e outros aspectos sobre sua organização, tais como Estatuto do Magistério e Planos de Carreira, bem como sobre o Conselho Municipal de Educação (CME). Bases de dados tais como Sistema Estadual de Dados Estatísticos (SEADE) e Instituto Brasileiro de Geografia e Estatística (IBGE) também foram consultadas.

\section{A Gestão numa Perspectiva Democrática e suas Relações com a Qualidade da Educação Infantil}

Em pesquisa de âmbito nacional, concluída em 2012, Campos (2012, coord.) detectou a escassez de trabalhos sobre gestão na El, refletindo sobre as implicações de tal ausência. A autora destaca as especificidades do trabalho na El que exigiriam, por isso, pesquisas mais focadas na gestão dessa etapa educacional visando a melhorar os padrões de qualidade até então vigentes em nosso país.

Como decorrência dessa escassez no campo da pesquisa, quando estudos dessa natureza são propostos um de seus desafios é justamente buscar referências para sustentar 
suas análises. Tendo em vista tal desafio, neste trabalho nos reportamos a conceitos mais gerais, especialmente no que se refere à gestão.

Com relação ao conceito de gestão, assumimos as definições propostas por Vitor Paro (1993; 2001; 2010). Segundo esse autor: "A atividade administrativa [gestão] não se dá no vazio, mas em condições históricas determinadas para atender a necessidades e interesses de pessoas e grupos" (PARO, 1993, p. 13). Embora se trate de um princípio amplo sobre administração, consideramos sua pertinência para refletir sobre a gestão na e da El. Assim, também no âmbito da El sua gestão - ou administração - deve ser compreendida em sua historicidade, como um dos elementos que compõem toda a complexidade que envolve essa etapa educacional.

Ainda com base em Paro (1993; 2001; 2010), compreendemos que a administração se apresenta como uma necessidade humana e diz respeito ao processo de mediação, já que o ser humano, sendo capaz de estabelecer objetivos e meios para o seu alcance, não vive isolado, mas em relação com outros seres humanos. Sendo assim, para o alcance de determinados fins, faz-se necessária uma mediação, que, nesse caso, se daria por meio da administração, que pode ser compreendida, em termos gerais, sob duas dimensões: a racionalização do trabalho e a coordenação do esforço humano coletivo. Conforme esse autor, ainda prevalece no senso comum a ideia de que a gestão - que ele toma como sinônimo de administração - necessariamente se vincula a relações "de mando e submissão" (PARO, 2001, p. 49), esclarecendo que, ao contrário, o que é específico ao conceito de gestão é o "seu caráter de mediação para a concretização de fins" (PARO, 2001, p. 49). Evidentemente essa mediação pode ocorrer por meio de relações hierárquicas e autoritárias; mas, tal ocorrência não significa a inexistência de outras possibilidades e, neste caso, concordamos com o autor sobre a ideia de que, numa perspectiva mais ampla de democracia, para haver coerência entre os fins e os meios para seu alcance, a gestão pode e deve se dar de modo democrático.

Ao considerarmos tal conceito de gestão, torna-se necessário, então, explicitar quais seriam os fins, os objetivos específicos da El. Do ponto de vista legal, temos definições de ordem mais geral (BRASIL; CF-1988; BRASIL; ECA-1990; BRASIL; LDB-1996; 2013) até aquelas mais especificamente relacionadas às práticas a serem desenvolvidas nas unidades de El. Em que pesem as contradições presentes nessas normativas, impossíveis de abordar nos limites deste trabalho, tomamos como referência para explicitar os objetivos mais amplos da El o que está contido na Resolução n. 5, de 17 de dezembro de 2009, que define as Diretrizes Curriculares Nacionais para a EI (DCNEI) (BRASIL, 2009a). Assim, as DCNEI, em seu artigo Art. $7^{\circ}$, definem que "a proposta pedagógica das instituições de Educação Infantil deve garantir que elas cumpram plenamente sua função sociopolítica e pedagógica”, dentre outras maneiras,

[...] construindo novas formas de sociabilidade e de subjetividade comprometidas com a ludicidade, a democracia, a sustentabilidade do planeta e com o rompimento de relações de dominação etária, socioeconômica, étnico-racial, de gênero, regional, linguística e religiosa (BRASIL, 2009a, grifos nossos).

No que se refere especificamente aos objetivos da El, o Art. $8^{\circ}$ determina que:

A proposta pedagógica das instituições de Educação Infantil deve ter como objetivo garantir à criança acesso a processos de apropriação, renovação e articulação de 
A Gestão da Educação Infantil em 12 Municípios Paulistas

conhecimentos e aprendizagens de diferentes linguagens, assim como o direito à proteção, à saúde, à liberdade, à confiança, ao respeito, à dignidade, à brincadeira, à convivência e à interação com outras crianças (BRASIL, 2009a).

No mesmo Art. $8^{\circ}$, define-se que as Propostas Pedagógicas das instituições de El deverão garantir "a participação, o diálogo e a escuta cotidiana das famílias, o respeito e a valorização de suas formas de organização", bem como "[...] o estabelecimento de uma relação efetiva com a comunidade local e de mecanismos que garantam a gestão democrática e a consideração dos saberes da comunidade [...]" (BRASIL, 2009a, grifos nossos).

Para além dos objetivos, a Resolução que estabelece as DCNEI também se refere aos princípios democráticos de gestão que estão indicados, de forma mais geral, em nossa Constituição Federal (BRASIL 1988) e na LDB (BRASIL, 1996). Entende-se, ademais, que para respeitar os princípios éticos, políticos e estéticos definidos no Art. $6^{\circ}$, e tendo em vista a definição de gestão como mediação (PARO, 2001) que deve levar em conta a adequação entre meios e fins determinados, na El faz-se necessária uma gestão efetivamente democrática. A gestão - ou administração -, numa perspectiva democrática, não pode se limitar às relações estabelecidas no âmbito de cada unidade, mas, antes, deve se configurar também nas relações entre as unidades e os órgãos intermediários ou centrais de poder das redes ou sistemas de ensino público, garantindo-se, dessa forma, coerência entre meios e fins. Nesse sentido, concordamos com Luiz Dourado (1998) quando o autor afirma que a administração escolar possui um caráter eminentemente político em todas as suas instâncias:

\begin{abstract}
A administração escolar configura-se, antes do mais, em ato político, na medida em que requer sempre uma tomada de posição. A ação educativa e, consequentemente, a política educacional em qualquer das suas feições não possuem apenas uma dimensão política, mas é sempre política, já que não há conhecimento, técnica e tecnologias neutras, pois todas são expressão de formas conscientes ou não de engajamento (DOURADO, 1998, p. 82).
\end{abstract}

Assim, a qualidade da Educação Infantil se relaciona não apenas aos insumos disponíveis, conforme estudos de Denise Carreira e José Marcelino de Rezende Pinto (2007), ou aos aspectos apontados em diferentes estudos sobre o tema (CAMPOS; CRUZ, 2006; CAMPOS; FULLGRAF; WIGGERS, 2006; ZABALZA, 1998). A qualidade, conforme aqui entendida, relaciona-se também à coerência entre meios e fins, ou seja, se também na $\mathrm{El}$ entendermos que a formação para a convivência democrática (MOSS, 2009) e para a superação de toda ordem de desigualdades deva estar presente, sua gestão necessariamente deve estar baseada numa forma de mediação democrática, seja entre os sujeitos que convivem na unidade, seja entre estes e aqueles que ocupam os órgãos intermediários e centrais da estrutura educacional. Nesse sentido, a gestão democrática é tomada aqui como um indicador de qualidade.

Com base em tais princípios, a seguir apresentamos dados sobre a gestão das redes e sistemas de ensino de 12 municípios, analisando suas condições e as possíveis consequências para a qualidade da $\mathrm{El}$, ou, em outras palavras, analisando as relações entre os fins da $\mathrm{El}$ e os meios adotados para a sua consecução. 
A Gestão da Educação Infantil em 12 Municípios Paulistas

\section{A Oferta de Educação Infantil em 12 Municípios Paulistas}

Os municípios que participaram da primeira etapa do estudo são, em sua quase totalidade, de pequeno porte, conforme classificação do IBGE. Ou seja, são municípios com menos de 100 mil habitantes. Apenas um município conta com população acima desse número. Os outros 11 municípios estão dentro da faixa entre sete e 42 mil habitantes.

O fato de serem municípios pequenos já apresenta, em si, um desafio para a gestão da educação pública municipal, refletindo-se, assim, sobre a gestão da El. Pinto (2014, p. 628), com base em dados do IBGE, esclarece que "cerca de $70 \%$ dos municípios brasileiros possuíam, em 2010, até 20 mil habitantes". Sobre essa constatação, o autor afirma existir grandes desafios aos municípios de pequeno porte no que se refere à educação,

\section{[...] seja do ponto de vista da gestão, seja do planejamento da sua rede de ensino, uma vez que apresentam instituições de natureza frágil, com profissionalismo questionável - no sentido weberiano de qualificação para a ocupação de um cargo em uma burocracia - dos agentes públicos, sem contar as relações clientelistas, aproximando-se do modelo de dominação carismática, também dentro da tipologia weberiana (PINTO, 2014, p. 628).}

Baseando-se novamente em dados do IBGE, o mesmo autor destaca, ainda, que no Brasil, em 2009, " $57 \%$ dos municípios não possuíam sequer uma secretaria exclusiva da educação, $48 \%$ não haviam constituído um sistema próprio de ensino e cerca de um terço não contava com um conselho municipal de educação com poderes deliberativos" (PINTO, 2014, p. 628).

Os desafios apontados pelo autor também foram encontrados, em certa medida, em nosso estudo. Além de serem municípios de pequeno porte, dentre os 12 analisados apenas quatro haviam se constituído como sistemas próprios, embora 10 já contassem com Secretarias de Educação e apenas um não contasse com Conselho Municipal de Educação. Constatamos, ainda, que apenas um município, o de menor porte e o mesmo que não contava com Conselho Municipal de Educação (CME), também não possuía Estatuto do Magistério nem Plano de Carreira. Os outros 11 apresentaram esses documentos, ainda que em alguns casos eles estivessem em descompasso com a legislação nacional vigente, uma vez que foram produzidos antes da Lei 11.738 (BRASIL, 2008), conhecida como "Lei do Piso".

Nos limites deste trabalho não vamos nos deter na discussão qualitativa dos documentos relativos aos Estatutos do Magistério e aos Planos de Carreira. Entretanto, vale mencionar que todos os 12 municípios integram em suas estruturas a docência na Educação Infantil sem diferenciação salarial entre os que atuam em creches e os que atuam em préescolas, ainda que persista a contratação de outros profissionais para atuar com as crianças que não são reconhecidos como docentes. Por outro lado, mais da metade dos municípios ainda não havia ajustado as jornadas de trabalho em respeito à Lei do Piso, com o estabelecimento de um terço da carga horária destinada a atividades de preparação e organização do trabalho com as crianças (BRASIL, 2008).

Quanto aos CME, a análise inicial dos documentos (leis e decretos de criação, bem como regimentos internos) evidencia que a EI não ocupa lugar central, uma vez que não estão previstas cadeiras específicas para profissionais, pais ou órgãos representativos dessa etapa educacional. Constatou-se, ainda, uma multiplicidade de funções e uma excessiva 
A Gestão da Educação Infantil em 12 Municípios Paulistas

representatividade de segmentos ligados ao poder executivo municipal, restando pouco espaço para representantes da sociedade civil.

Quanto à oferta de vagas para a El nesses municípios, os dados sugerem que ainda há grandes desafios. O quadro a seguir apresenta dados sobre a população na faixa de zero a cinco anos e o total de matrículas na El em cada município.

Quadro 1 - População e matrículas na El, por município

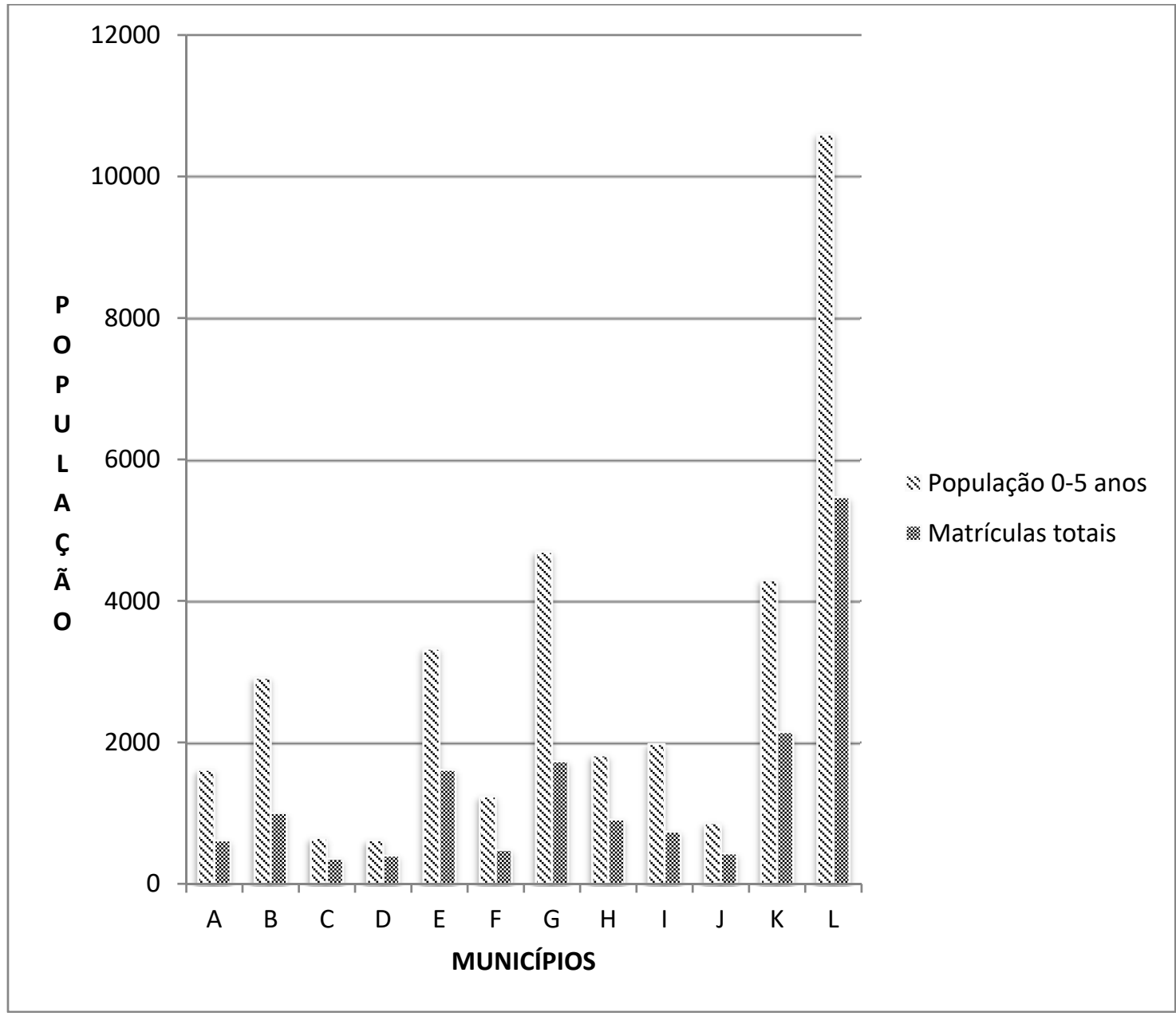

Fonte: Seade $(2011 ; 2013)$.

Mesmo sem desagregar as matrículas por faixa etária, e considerando os dados dos questionários, o quadro sugere que os desafios, em termos quantitativos, ainda são significativos. Além da Emenda Constitucional n. 59 (EC 59) e da nova redação dada à LDB em 2013 (BRASIL, 2009; 2013), vale lembrar que o atual Plano Nacional de Educação - PNE - (BRASIL, 2014) reafirmou a universalização das matrículas de crianças de quatro e cinco anos até 2016 e estabeleceu, ainda, que até o final da sua vigência $50 \%$ das crianças de zero a três anos tenham acesso à creche. Conforme análise de Pinto (2014, p. 642) sobre as metas do PNE para a El, considerando a situação do país como um todo, o esforço deve ser significativo, implicando "um adicional de 4,5 milhões de novas matrículas".

Durante a aplicação dos questionários, em apenas um município a respondente afirmou não atender $100 \%$ das crianças de quatro e cinco anos, havendo, em 2014 , lista de espera também para a pré-escola. Nos demais municípios todos os respondentes afirmaram atender 
$100 \%$ dessa faixa etária. Ocorre que, assim como Kramer e Nunes (2007), constatamos que nenhum dos respondentes conhecia o número de crianças de zero a cinco anos residentes nos municípios. Essa foi uma pergunta específica do questionário e, ao se depararem com ela, a maioria afirmou à pesquisadora que esse dado poderia ser obtido no censo do IBGE ou na prefeitura, não se dando conta de que a informação era relevante para os dirigentes da própria SME. Em dois casos os respondentes observaram que a questão tinha relação com a outra, sobre percentual de atendimento da demanda, e, durante a conversa, reconheceram esse desconhecimento como um "problema". Além de não ser possível determinar os percentuais de atendimento com segurança, o outro problema decorrente do desconhecimento da população na faixa etária é a impossibilidade de planejar e estabelecer estratégias de ampliação da oferta. Nas palavras de Kramer e Nunes, tal situação "[...] dificulta o delineamento de políticas públicas municipais de educação infantil, já que não é possível traçar políticas sem saber quantas crianças com direito à educação infantil residem no município" (KRAMER; NUNES, 2007, p. 428).

Quanto à oferta de educação às crianças de zero a três anos, 10 respondentes admitiram haver listas de espera e que o município não conseguia atender a todas as famílias que procuravam por vagas em creche. Com relação a essa questão, é importante lembrar que, ao tratarmos da cobertura em termos de faixa etária (zero a três, principalmente), alguns dados podem levar a erros de interpretação, por isso, tivemos o cuidado de perguntar sobre a oferta no interior dessa faixa e com que idade as crianças começavam a ser matriculadas. Verificamos, assim, que em 10 municípios o ingresso na creche ocorre a partir dos quatro ou seis meses; em um as crianças ingressam a partir dos 12 meses e, em outro, apenas a partir dos 24 meses, ou seja, nestes dois não há atendimento para bebês. Em um desses municípios que não atende bebês, a respondente explicitou que o custo elevado seria o motivo de não terem berçários.

Ainda com relação à oferta para a faixa de zero a três anos, vale mencionar o caso do município E. A Secretária nos afirmou que atendia 100\% da demanda manifesta, ou seja, que todos que procuravam por uma vaga nas creches eram contemplados. Indagamos se havia normas quanto à razão crianças por adulto. A resposta foi de que não havia determinações nesse sentido e que a opção política era matricular todas as crianças cujas famílias procurassem por uma vaga, pois do contrário a SME seria acionada judicialmente pela Promotoria Pública, como já ocorrera em anos anteriores. Esse caso é exemplar para a discussão quanto ao processo de "exigibilidade judicial do direito à educação" (SILVEIRA, 2012 , p. 355) versus a garantia de padrões de qualidade. O que podemos afirmar é que a qualidade certamente é afetada com uma política de matricular as crianças indiscriminadamente, ou, sem respeitar, por exemplo, um número limite de crianças por professor.

Nos dois municípios em que a matrícula só é aceita a partir dos 12 (município C) ou 24 meses (município A), as observações feitas pelas respondentes durante a aplicação dos questionários também merecem destaque. Em ambos os casos a Secretária e a Coordenadora de $\mathrm{El}$, respectivamente, afirmaram que, como seus municípios são pequenos e elas conhecem as famílias, conseguem "selecionar" aquelas que, em suas palavras, "precisam realmente da creche". Ao especificarem quem seriam essas famílias, ambas mencionaram aquelas que estariam em situação de extrema pobreza, mães solteiras ou 
separadas, mulheres que não teriam nenhum parente com quem contar, como avós ou tias das crianças. Essa situação nos remete a um problema que também tem a ver com o porte dos municípios e o tipo de relações estabelecidas entre o poder público e a população. Nesse caso, a proximidade entre as duas esferas, em lugar de propiciar maior capacidade de pressão da população sobre o poder público municipal, serve para que este estabeleça, a partir de critérios absolutamente subjetivos e ao arrepio da lei, quem terá o direito a uma vaga na creche.

No município A, onde estudos de caso foram realizados, foi possível captar, ainda, outros mecanismos informais de alívio da pressão por vagas. Quando as famílias que estão em listas de espera são chamadas, não podem escolher o período (matutino, vespertino ou integral) e devem se apresentar no dia seguinte ao chamado, perdendo a vaga caso isso não ocorra. Quando as crianças ingressam há um período de "adaptação". Durante esse período, se a criança chora a família é imediatamente chamada, por telefone, para ir buscá-la. Essas medidas são adotadas sob a orientação - verbal - da SME. O que constatamos, durante as observações em uma unidade de El desse município, é que não há esforços para que as crianças que choram se envolvam em atividades interessantes e desejem permanecer na unidade. Nos limites deste trabalho, não temos como avançar na análise mais profunda desta e de outras observações sobre o dia a dia dessa unidade, mas, com base apenas no que apresentamos, é possível verificar como a política educacional, por vezes de modo não prescrito oficialmente, atua para resolver questões de demanda, incidindo negativa e diretamente sobre a vida das famílias e das próprias crianças. Nesse caso, tanto para as famílias quanto para as crianças, o primeiro problema é conseguir uma vaga, o segundo, quiçá mais dramático, é ter de passar por constrangimentos como o não acolhimento da criança.

Quanto à estrutura das SME, existentes em 10 dos 12 municípios participantes, observamos bastante fragilidade, especialmente quanto ao número de profissionais que se ocupam diretamente da EI. Assim, no organograma das 10 SME constatamos que em apenas quatro deles havia também um coordenador de $E I$, sendo que, destes, apenas dois ( $B$ e $L$ ) contavam com cargos de supervisores (ou equivalentes) cujo trabalho era acompanhar as atividades de creches e pré-escolas. Mesmo em municípios como E, G e K, com população entre 38 e 41 mil habitantes e número de matrículas na El variando entre 1.600, 1.700 e 2.200, respectivamente, não havia um corpo de supervisores na estrutura da SME voltado ao suporte e acompanhamento do trabalho nas unidades. No município L, com população acima dos 100 mil habitantes, havia dois "assessores para assuntos de El" e oito coordenadores pedagógicos alocados na SME, sendo estes últimos os profissionais que respondiam tanto pela função de supervisor quanto de formador, cada qual se responsabilizando por quatro unidades de El da rede.

Dentre os 12 municípios, em sete havia sistemas apostilados de ensino para a El, para crianças a partir dos três anos de idade. Nesse caso, a compra de materiais apostilados sugere relação com a estrutura das redes municipais que, dada a falta de pessoal, opta pela assunção de modelos pedagógicos padronizados, muitas vezes sob a justificativa de que, além de garantir igual qualidade para todas as unidades, as empresas também oferecem formação aos professores (ADRIÃO et al., 2009). Destaque-se que essa prática vem se ampliando no estado de São Paulo, tal como demonstrado em estudos de Adrião et al. (2009); Pinheiro; Adrião (2009) e Nascimento (2012). 
Ainda com relação à estrutura das SME, chama a atenção a diferença salarial para o cargo de Secretário da Educação entre os municípios, variando entre aproximadamente três e oito mil reais. Em todos os casos o provimento para esse cargo depende de indicação do Poder Executivo e não há exigências de formação ou experiência profissional na área.

Com relação à estrutura de gestão no âmbito das unidades, constatamos que apenas em um município não havia cargo de diretor; nesse caso, havia um coordenador. Nos outros 11 todas as unidades contavam com um cargo de "diretor de escola"; em nenhum havia cargos de vice-diretor e sete deles contavam com coordenadores pedagógicos, um por unidade. $O$ município $E$ se destaca do conjunto porque foi o único em que encontramos um modelo bastante diverso no que se refere à estrutura de gestão das unidades. Nele havia um diretor e um vice-diretor responsáveis por sete pré-escolas e dois diretores que respondiam por sete creches. Conforme explicação da secretária de educação, esses dois diretores e um vice atuavam em sistema de rodízio entre as unidades.

Em relação ao provimento dos cargos de diretor das unidades de $\mathrm{El}$, em todos os casos ele ocorre por meio de indicação política, constituindo-se como cargo de confiança do Poder Executivo Municipal. Em um desses municípios, a respondente afirmou ter havido mudança na legislação local para adequá-la ao perfil de indicados políticos ao cargo de direção, de modo que, além de não se exigir que o candidato fosse professor da rede municipal, passouse a aceitar apenas o ensino médio como qualificação mínima para o posto. Esse é o caso que melhor evidencia como relações clientelistas - mencionadas por Pinto (2014) em estudo anteriormente citado - ainda se sobrepõem aos interesses públicos que deveriam presidir a organização de um sistema ou de uma rede pública de educação. Nesse sentido, também é importante mencionar que, em trabalho publicado por Kramer e Nunes (2007), com base em pesquisa realizada no Estado do Rio de Janeiro, evidenciou-se a existência de intervenções político-partidárias na indicação de nomes tanto para a gestão das unidades quanto para a assunção de funções técnicas no âmbito das SME daquele Estado. Como um dos fatores que favorecem esse tipo de ocorrência, as autoras mencionam a gestão centralizada da política, que não favorece a participação dos professores em sua elaboração, implementação e acompanhamento (KRAMER; NUNES, 2007). Finalmente, vale lembrar que também Lígia Aquino (2009), ao refletir sobre a gestão democrática na El, já argumentava, em 2009, que os desafios para essa etapa educacional vêm aumentando e se tornando cada vez mais complexos, do que resultariam exigências também crescentes em relação à formação tanto dos gestores quanto dos professores dessa etapa.

Além do cargo de direção das unidades de El configurar-se como sendo de confiança do Poder Executivo nos 12 municípios que participaram de nosso estudo, em todos os casos também há expressiva diferenciação entre a remuneração de diretores e docentes e, em especial, em relação ao cargo de educador, auxiliar ou pajem, termos que designam o profissional que, embora atuando diretamente com as crianças, não é contratado como professor. Antes de apresentarmos alguns exemplos dessa diferenciação, cumpre esclarecer que os dados referentes aos salários foram obtidos por meio dos questionários. Estes, por sua vez, indicavam faixas salariais, e não valores absolutos. Em alguns municípios, entretanto, os respondentes mencionaram valores exatos durante a aplicação dos questionários. Isso explica a diferença na apresentação dos exemplos a seguir. 
A Gestão da Educação Infantil em 12 Municípios Paulistas

No município E, com população próxima aos 40 mil habitantes, enquanto um diretor que atua na EI recebia salário base (sem considerar outros benefícios) de $R \$ 3.800,00$, em 2014, uma professora dessa etapa recebia entre $R \$ 1$ mil e $R \$ 2$ mil reais (com benefícios) para uma jornada de $25 \mathrm{~h}$, ao passo que uma "auxiliar de recreação", com jornada de $40 \mathrm{~h}$ semanais, recebia um valor líquido de $R \$ 727,00$.

Outros dois casos que destacamos são o menor e o maior municípios, em termos populacionais. O município D, com pouco mais de sete mil habitantes, em 2014 pagava a um diretor de unidade de El um salário de $\mathrm{R} \$ 2.476,00$, sem haver qualquer outro benefício, por uma jornada de 40h semanais; já um "auxiliar de creche" recebia, pela mesma jornada, menos de mil reais, enquanto um professor de El, para uma jornada de $30 \mathrm{~h}$, recebia em torno de $\mathrm{R} \$ 1.350,00$.

Já o município L, com população superior a 100 mil habitantes, pagava um salário superior a $\mathrm{R} \$ 3.000,00$ aos diretores das unidades de $\mathrm{El}$, enquanto os professores recebiam, por uma jornada de $25 \mathrm{~h}$, entre $\mathrm{R} \$ 1.950,00$ (contratados temporariamente) e $R \$ 2.450,00$ (concursados). Já os "auxiliares de desenvolvimento infantil", com jornada de 40h semanais, recebiam mais que um salário mínimo, porém menos que mil reais. O salário mínimo paulista em 2014 equivalia a um valor entre $R \$ 810,00$ e $R \$ 820,00$. Destaque-se que nesse caso há outra peculiaridade: coexistem duas formas de contratação de professores, embora todos tenham a mesma formação e jornada, refletindo-se tal diferenciação no valor dos salários. Embora este tema não possa ser aqui melhor discutido, é digno de nota como os municípios vêm adotando variadas estratégias que, inferimos, visam a reduzir seus gastos com folha de pagamento.

\section{Considerações Finais}

Conforme mencionamos no início deste trabalho, nosso objetivo mais amplo é analisar as relações entre a organização da gestão e os padrões de qualidade na oferta de El, valendonos, para tanto, da análise de dados de um conjunto de redes e sistemas municipais de educação localizados no Estado de São Paulo. Como a pesquisa continua em andamento, com aprofundamento da análise documental e realização dos estudos de caso, neste trabalho apresentamos os resultados obtidos por meio da aplicação de questionários. Estes resultados sugerem a existência de: estruturas frágeis, tanto quantitativa quanto qualitativamente; número insuficiente de profissionais para apoio e acompanhamento das unidades de El; desconhecimento de dados fundamentais para o planejamento e ampliação da oferta de vagas, mesmo para a pré-escola; relações de mando e submissão, com brechas para a ocorrência de clientelismo; desigualdades em termos de remuneração e jornadas; permanência de contratação de "outros" profissionais para atuar diretamente com as crianças; desrespeito ou descumprimento à legislação educacional vigente no país desde 1996.

Verificamos a permanência de modelos hierárquicos na organização das SME e das unidades de El, com a definição dos cargos de gestão marcada, ainda, pelo controle do Poder Executivo, sem a participação dos profissionais da educação e da população usuária. Pesquisas sobre gestão escolar, ainda que com o foco no ensino fundamental, são úteis para refletirmos sobre os possíveis efeitos desse sistema de indicação de diretores. O que esses estudos têm demonstrado é que, no mais das vezes, "[...] esse procedimento tende a fazer com que o compromisso do diretor acabe se dando apenas com os interesses da pessoa ou 
A Gestão da Educação Infantil em 12 Municípios Paulistas

grupo político que o nomeia" (PARO, 1996, p. 19). Para além desse risco, ressaltamos que em nenhum dos municípios encontramos a definição de critérios para a indicação de diretores, tais como ter conhecimento e experiência na El. Vale lembrar, assim, o alerta feito por Campos (2012) sobre as especificidades dessa etapa educacional que exigiriam, por isso, conhecimentos próprios por parte daqueles que assumem a gestão do trabalho, especialmente no âmbito das unidades (creches e pré-escolas).

Ainda que 10 municípios tenham estruturado secretarias de educação, com organograma próprio, o número de profissionais cujo trabalho se dirige à El é claramente insuficiente, mesmo nos municípios maiores. Considerando que dos 12 municípios oito não se constituíram como sistemas próprios de educação, a situação parece ser mais grave, pois todos os respondentes destes municípios admitiram que as Diretorias de Ensino do sistema estadual paulista, a quem ficam vinculados, não realizam acompanhamento (supervisão) nem oferecem suporte pedagógico às unidades de El.

Essa fragilidade em termos de estrutura das SME e DPE também pode explicar, em parte, o fato de que mais de $50 \%$ desses municípios tenham adotado sistemas apostilados de ensino, comercializados por empresas privadas. Embora não tenhamos completado os estudos de caso, é possível inferir que alguns direitos das crianças não estejam sendo respeitados com a adoção desse tipo de material. Estudos de Nascimento (2012) e de Correa e Adrião (2014) que analisaram materiais apostilados para a El informam que sua adoção se confronta com a finalidade dessa etapa educacional, determinada pelo artigo 29 da LDB ("desenvolvimento integral" da criança), bem como com os princípios estabelecidos pelas DCNEI para a organização do trabalho na El (o brincar e as interações).

Concluímos, por ora, e mesmo antes de analisar o dia a dia das unidades existentes nos municípios analisados, que a qualidade da El ainda é tema para muito debate e, principalmente, para muito investimento. Estudos sobre financiamento da educação têm indicado a necessidade de maior aporte de recursos para essa etapa educacional, bem como maior participação do governo federal, uma vez que os municípios são os entes federados com menor capacidade financeira (PINTO; ALVES, 2011). Os dados levantados em nossa pesquisa reforçam, com alguns detalhes, essa necessidade, buscando evidenciar que mesmo numa região pertencente a um dos estados mais ricos da federação, as relações entre a gestão e a qualidade da oferta de EI deixam claro que essa etapa da educação básica brasileira ainda não recebe a devida atenção.

\section{Referências}

ADRIÃO, Theresa et al. Uma modalidade peculiar de privatização da educação pública: a aquisição de 'sistemas de ensino' por municípios paulistas. Educação e Sociedade, Campinas, v. 30, n. 108, p. 799-818, out. 2009.

AQUINO, Ligia Maria Leão. A gestão democrática nas instituições de educação infantil: questões para pensar a formação de gestores. Educação em Foco, Juiz de Fora, v. 13, n. 2, p. 251-268, set. 2008/fev. 2009.

BHERING, Eliana; NEZ, Tatiane Bombardelli de. Envolvimento de Pais em Creche: Possibilidades e Dificuldades de Parceria. Psicologia: Teoria e Pesquisa, Brasília, v. 18, n.1, jan./abr. 2002. 
A Gestão da Educação Infantil em 12 Municípios Paulistas

BORGHI, Bautista Quintino. As escolas infantis como serviço de qualidade. In: ZABALZA, Miguel A. Qualidade em Educação Infantil. Porto Alegre: ARTMED, 1998. P. 97-118.

BRASIL. Constituição da República Federativa do Brasil. Diário Oficial da União, Brasília, 05 out. 1988. P. 1.

BRASIL. Lei n 8.069, de 13/07/1990. Dispõe sobre o Estatuto da criança e do adolescente (ECA). Diário Oficial da União, Brasília, 1990.

BRASIL. Lei nº 9.394 de 20/12/1996. Lei de diretrizes e bases da Educação (LDB). Diário Oficial da União, Brasília, 1996.

BRASIL. CNE. Resolução $n^{\circ}$ 5, de 17 de dezembro de 2009. Fixa as Diretrizes Curriculares Nacionais para a Educação Infantil. Diário Oficial da União, Brasília, 18 dez. 2009a. Seção 1 , p. 18.

BRASIL. Emenda Constitucional n. 59 de 11 de novembro de 2009. Diário Oficial da União, Brasília, 12 nov. 2009b. P. 8.

BRASIL. Lei $n^{0} 12.796$, de 4 de abril de 2013. Altera a Lei n. 9.394, de 20 de dezembro de 1996, que estabelece as diretrizes e bases da educação nacional, para dispor sobre a formação dos profissionais da educação e dar outras providências. Diário Oficial da União, Brasília, 2013.

BRASIL. Lei n 13.004, de 25 de junho de 2014. Aprova o Plano Nacional de Educação - PNE e dá outras providencias. Diário Oficial da União, Brasília, 2014.

CAMPOS, Maria Malta (Coord.). A Gestão da Educação Infantil no Brasil. Relatório de pesquisa realizada pela Fundação Carlos Chagas e pela Fundação Victor Civita. São Paulo, 2012. Disponível em: <http://www.fvc.org.br/estudos-e-pesquisas/2011/pdf/relatoriofinal educacaoinfantil.pdf>. Acesso em: 01 nov. 2017.

CAMPOS, Maria Malta; CRUZ, Silvia H. Vieira. Consulta sobre Qualidade na Educação Infantil: o que pensam e querem os sujeitos deste direito. São Paulo: Cortez, 2006.

CAMPOS, Maria Malta; FULLGRAF, Jodete; WIGGERS, Verena. A qualidade da Educação Infantil brasileira: alguns resultados de pesquisa. Cadernos de Pesquisa, São Paulo, n. 127, 2006.

CARREIRA, Denise; PINTO, José Marcelino Rezende. Custo aluno-qualidade inicial, rumo à educação pública de qualidade no Brasil. São Paulo: Global; Campanha Nacional pelo Direito à Educação, 2007.

CÔCO, Valdete. Gestão na Educação Infantil - os processos de escolha dos dirigentes das instituições. In: SIMPÓSIO DA ASSOCIAÇÃO NACIONAL DE POLÍTICA E ADMINISTRAÇÃO DA EDUCAÇÃO, 24., 2009, Vitória. Anais... Vitória, 2009. Disponível em: <http://www.anpae.org.br/congressos_antigos/simposio2009/345.pdf>. Acesso em: 01 nov. 2017.

CORREA, Bianca Cristina. Possibilidades de Participação Familiar E Qualidade Na Educação Infantil. 2001. 196 f. Dissertação (Mestrado em Educação) - Faculdade de Educação, Universidade de São Paulo, São Paulo, 2001. 
A Gestão da Educação Infantil em 12 Municípios Paulistas

CORREA, Bianca Cristina. Considerações sobre qualidade na Educação Infantil. Cadernos de Pesquisa, São Paulo, n. 119, p. 85-112, 2003.

CORREA, Bianca Cristina. Democratização da Gestão Escolar na Educação Infantil: um caso e seus múltiplos significados. 2006. 247 f. Tese (Doutorado em Educação) - Faculdade de Educação, Universidade de São Paulo, São Paulo, 2006.

CORREA, Bianca Cristina; ADRIÃO, Theresa. O material apostilado utilizado em pré-escolas municipais paulistas: análise de dois casos. Revista Brasileira de Política e Administração da Educação- RBPAE, Goiânia, v. 30, n. 2, p. 379-396, maio/ago. 2014.

DOURADO, Luiz Fernandes. A escolha de dirigentes escolares: políticas e gestão da educação no Brasil. In: FERREIRA, Naura (Org.). Gestão Democrática da Educação: atuais tendências, novos desafios. São Paulo: Cortez, 1998.

FARIA, Ana Lúcia Goulart; PALHARES, Marina Silveira (Org.). Educação Infantil Pós-LDB: rumos e desafios. Campinas; São Paulo: Autores Associados - FE/UNICAMP; São Carlos: Editora da UFSCar; Florianópolis: Editora da UFSC, 1999.

GARCIA, Heloisa Helena G. de; MACEDO, Lino de. Reuniões de pais na Educação Infantil: modos de gestão. Cadernos de Pesquisa, São Paulo, v. 41, n. 142, jan./abr. 2011.

GUNNARSSON, Lars. A política de cuidado e educação na Suécia. In: ROSEMBERG, Fúlvia; CAMPOS, Maria Malta (Org). Creches e Pré-escolas no Hemisfério Norte. São Paulo: Cortez, 1998. P. 135-187.

HADDAD, Lenira. A Creche em Busca de Identidade. São Paulo: Loyola, 1993.

JENSEN, Jytte Juul. Educação Infantil na Comunidade Européia. In: SIMPÓSIO NACIONAL DE EDUCAÇÃO INFANTIL, 1., 1994, Brasília. Anais... Brasília, 1994. P. 157-164.

KRAMER, Sonia; NUNES, Maria Fernanda. Gestão pública, formação e identidade de profissionais de Educação Infantil. Cadernos de Pesquisa, São Paulo, v. 37, n. 131, p. 423454, maio/ago. 2007

MELLO, Ana Maria. Um diálogo com os diretores de creches e pré-escolas. In: ROSSETIFERREIRA, Maria Clotilde at. al. Os fazeres na Educação Infantil. São Paulo: Cortez, 1998.

MOSS, Peter. Introduzindo a política na creche: educação infantil como prática democrática. Psicologia USP, São Paulo, p. 417-436, jul./set. 2009.

NASCIMENTO, Maria Letícia B. P. As políticas públicas de educação infantil e a utilização de sistemas apostilados no cotidiano de creches e pré-escolas públicas. Revista Brasileira de Educação, Rio de Janeiro, v. 17 n. 49, p. 59-80, jan./abr. 2012.

PARO, Vitor Henrique. Administração Escolar: introdução crítica. 6. ed. São Paulo: Cortez, 1993.

PARO, Vitor Henrique. Eleição de Diretores: a escola pública experimenta a democracia. Campinas: Papirus, 1996.

PARO, Vitor Henrique. Escritos sobre Educação. São Paulo: Xamã, 2001. 
A Gestão da Educação Infantil em 12 Municípios Paulistas

PARO, Vitor Henrique. A educação, a política e a administração: reflexões sobre a prática do diretor de escola. Educação e Pesquisa, São Paulo, v. 36, n. 3, p. 763-778, 2010.

PINHEIRO Denise; ADRIÃO Theresa. Parcerias entre municípios paulistas e a esfera privada para a aquisição de "Sistemas de Ensino Apostilados" na Educação Infantil. 2009. Disponível em: <http://www.fclar.unesp.br/Home/Departamentos/CienciasdaEducacao/ RevistaEletronica/7_Parcerias_entre_municipios_paulistas_Denise_Pinheiro.pdf >. Acesso em: 01 dez. 2017.

PINTO, José Marcelino Rezende. Federalismo, descentralização e planejamento da educação: desafios aos municípios. Cadernos de Pesquisa, São Paulo, v. 44, n. 153, p. 624644, jul./set. 2014.

PINTO, José Marcelino Rezende; ALVES, Thiago. O Impacto Financeiro da Ampliação da Obrigatoriedade Escolar no Contexto do FUNDEB. Educação \& Realidade, Porto Alegre, v. 36, n. 2, p. 605-624, maio/ago. 2011.

ROSEMBERG, Fúlvia; CAMPOS, Maria Malta (Org.). Creches e Pré-Escolas no Hemisfério Norte. São Paulo: Cortez, 1998.

SILVEIRA, Adriana Dragone. Atuação do Tribunal de Justiça de São Paulo com relação ao direito de crianças e adolescentes à educação. Revista Brasileira de Educação, Rio de Janeiro, v. 17 n. 50, p. 353-497, maio/ago. 2012.

SOUZA, Solange Jobim; KRAMER, Sonia. Educação ou tutela? A criança de 0 a 6 anos. São Paulo: Loyola, 1991.

SPAGGIARI, Sergio. Considerações críticas e experiências de gestão social. In: BONDIOLI, Anna; MANTOVANI, Susanna. Manual de Educação Infantil: de 0 a 3 anos. 9. ed. Porto Alegre: Artmed, 1998.

ZABALZA, Miguel A. Os dez aspectos-chave de uma Educação Infantil de qualidade. In: ZABALZA, Miguel A. Qualidade em Educação Infantil. Porto Alegre: ARTMED, 1998. P. 49-61.

Bianca Cristina Correa é professora doutora do curso de Pedagogia da Faculdade de Filosofia, Ciências e Letras de Ribeirão Preto da Universidade de São Paulo (FFCLRP-USP) e do Programa de Pós-Graduação em Educação na mesma instituição.

E-mail: biancacorrea@ffclrp.usp.br 


\title{
Editores do volume 8
}

José Marcelino de Rezende Pinto - Universidade de São Paulo, São Paulo/SP, Brasil

Nalú Farenzena - Universidade Federal do Rio Grande do Sul, Porto Alegre/RS, Brasil

\section{Comitê Editorial}

José Marcelino de Rezende Pinto - Universidade de São Paulo, Brasil

Juca Gil - Universidade Federal do Rio Grande do Sul, Brasil

Theresa Adrião - Universidade Estadual de Campinas, Brasil Ângelo

Ricardo de Souza - Universidade Federal do Paraná, Brasil

Márcia Aparecida Jacomini - Universidade Federal de São Paulo, Brasil

\section{Conselho Editorial}

\section{Alejandro Morduchowicz}

Universidad Pedagógica, Provincia de Buenos Aires, Argentina

Fernanda Saforcada

Universidade de Buenos Aires, Argentina

Jacques Velloso

Universidade de Brasília, Brasil

João Monlevade

Senado Federal, Brasil

Jorge Abrahão de Castro

Instituto de Pesquisa Econômica Aplicada / IPEA, Brasil

Juca Gil

Universidade Federal do Rio Grande do Sul, Brasil

Lisete Regina Gomes Arelaro

Universidade de São Paulo, Brasil

Luis Carlos Sales

Universidade Federal do Piauí, Brasil

Luiz de Sousa Junior

Universidade Federal da Paraíba, Brasil

Luiz Fernandes Dourado

Universidade Federal de Goiás, Brasil

Magna França

Universidade Federal do Rio Grande do Norte, Brasil

\section{Maria Beatriz Luce}

Universidade Federal do Pampa, Brasil

Universidade Federal do Rio Grande do Sul, Brasil

Marcos Edgar Bassi

Universidade Federal do Paraná, Brasil

\author{
Maria Dilnéia Espíndola Fernandes \\ Universidade Federal de Mato Grosso do Sul, Brasil \\ Nalú Farenzena \\ Universidade Federal do Rio Grande do Sul, Brasil \\ Nelson Cardoso do Amaral \\ Universidade Federal de Goiás, Brasil \\ Nicholas Davies \\ Universidade Federal Fluminense, Brasil \\ Rosana Evangelista Cruz \\ Universidade Federal do Piauí, Brasil \\ Rosana Gemaque \\ Universidade Federal do Pará, Brasil \\ Robert E. Verhine \\ Universidade Federal da Bahia, Brasil \\ Romualdo Portela de Oliveira \\ Universidade de São Paulo, Brasil \\ Theresa Adrião \\ Universidade Estadual de Campinas, Brasil \\ Tristan McCowan \\ University of London, Reino Unido \\ Vera Jacob \\ Universidade Federal do Pará, Brasil \\ Vera Peroni \\ Universidade Federal do Rio Grande do Sul, Brasil \\ Vitor Henrique Paro \\ Universidade de São Paulo, Brasil
}

\section{Equipe editorial}

Apoio ao Comitê Editorial: Patrícia Balthazar Garcia

Diagramação, Revisão de português e normalização: Edson Leonel de Oliveira

Revisão de inglês: Ananyr Porto Fajardo 